\title{
Challenges and Ethical Issues Related to COVID-19 Contact Tracing Teams in Turkey
}

\author{
Sukran Sevimli $\mathbb{D}^{1,2}$ \\ Barıș Sarp Sevimli $\mathbb{D}^{2}$ \\ 'Department of Medical History and \\ Ethics, Van Yuzuncu YIl University, \\ Medical School, Van, Turkey; \\ ${ }^{2}$ Department of Periodontology, \\ Hacettepe University Faculty of \\ Dentistry, Ankara, Turkey
}

\begin{abstract}
Objective: The purpose of this study was to determine and evaluate the challenges and ethical issues faced by COVID-19 filiation (contact tracing) teams and report the experiences of team members.

Methods: This is a descriptive study conducted to evaluate the performance of contact tracing field teams established by the Ministry of Health to identify, refer, and follow-up persons who tested positive for COVID-19 and their contacts. Reports were collected from various Turkish medical associations, the Turkish Ministry of Health, online news sources, and online interviews published between 11 March 2020 and 18 April 2021.

Results: A total of 32 reports published by the Turkish Ministry of Health, various medical associations in Turkey, and the Turkish Academy of Science, together with a number of online media reports on issues involving contact tracing teams, were reviewed. While the activities of the teams were overall found to be of benefit during the pandemic, numerous factors negatively impacting their success were identified. These factors included insufficient social support, wherein the fundamental bioethical values of solidarity, responsibility, respect, and trust were not adopted on a societal level, as well as issues involving the teams themselves, such as lack of time to properly conduct their work, inadequate communication skills and/or personal issues.

Conclusion: Studies conducted by the contact tracing teams were of vital importance in managing the pandemic. The teams were especially effective in reaching both educated and uneducated segments of the society, in diagnosing cases, and in informing the public regarding the pandemic. Evaluating the experiences of the contact tracing teams deployed in Turkey is of vital importance to ensure better preparation for any future pandemics.
\end{abstract}

Keywords: contact tracing team, filiation, pandemic, COVID-19, ethical issues

\section{Introduction}

The virus that emerged in Wuhan, Hubei province of China, causing numerous severe health problems, subsequently spread rapidly around the world and was named SARS-CoV-2 (COVID-19) by the World Health Organization (WHO), on January 30, 2020. Less than two weeks later, on February 11, 2020, the WHO declared COVID-19 an international public health problem and a pandemic. ${ }^{1}$ The reasons for designating COVID-19 as a pandemic included its basic reproductive coefficient, mortality rate, the ratio of asymptomatic and mild cases, contagion period, and its spread via airborne transmission.

The primary measures taken by governments to contain COVID-19 have involved the traditional public health tools of testing, contact tracing, and isolation. Health authorities immediately declared that the general public should undertake
Correspondence: Sukran Sevimli Van Yuzuncu Yıl University, Medical School, Van, 06580, Turkey

Email sukransevimli@gmail.com 
precautions such as hand-washing, social distancing, and mask-wearing to prevent transmission and thus protect public health. Further recommendations included healthy eating, regular sleep, exercise, and avoiding crowded environments.

Moreover, in addition to employing important measures such as contact tracing and monitoring, governments also increased the number of intensive care unit services and the sharing of information regarding treatment modalities. The WHO stated contact tracing to be an important strategy to disrupt COVID-19 transmission chains and reduce the associated mortality rates. ${ }^{2}$ In Turkey, the Ministry of Health founded filiation (contact tracing) teams as a primary measure and developed a mobile application program to determine suspected carriers and/or those testing positive for COVID-19 positive and warn them.

\section{The Filiation Team/Contact Tracing Field Team}

The French word filiation has been used for contact tracing studies performed to identify the index case (patient zero) of infectious diseases since the nineteenth century. ${ }^{3-5}$ One of the most effective methods in minimizing or halting the spread of infectious diseases is tracing the contact chain and/or finding the source of the disease. The filiation or contact tracing field system was established on 5 February 2015 by the Turkish Ministry of Health in the fourteenth article of the section on communicable diseases, immunization, and epidemic control for the regulation of community health centers and affiliated units, as published in its official gazette, No. $29258 .^{6}$ This article stated that contact tracing teams would conduct various field investigations into the epidemic, communicable disease followup studies and surveillance studies, and record infectious disease cases in their regions of responsibility. ${ }^{7}$ Each contact tracing team was to be managed by a "Case Tracking and Filiation Management Center" located at each Provincial Health Directorate; currently, the total number of such teams in Turkey exceeds 16,000. As of April 14, 2020 , contact tracing teams had visited $95.8 \%$ of individuals who tested positive for COVID-19. The Turkish Health Minister F. Koca reported an average of 4.5 contacts per confirmed case. ${ }^{8}$

Each contact tracing team consists of three members: one doctor, one healthcare worker (such as a nurse or medical technician), and one driver. They conduct their studies incorporating the following three algorithms: the adult treatment algorithm, COVID-19 home tracking algorithm, and COVID-19 inpatient algorithm. ${ }^{9}$ The teams, wearing protective clothing, visit suspected cases to record the relevant information, including contacts, and explain the health measures necessary for patients to take. The field team then follows up on the patients' contacts at the latters' addresses, ensuring that they are kept under observation for 14 days, and treating those who test positive. Consequently, the work performed by the contact tracing teams breaks the chains of transmission by identifying contacts and following up on them for a period of 14 days. The contact tracing teams also ensure that the patient's close relatives and friends receive proper follow-up as well.

\section{The Mobile Application (App) Program "Life Fits in the House" (LFS)}

The Turkish Ministry of Health has developed a mobile application called "Life Fits in the House", whereby a person who obtains a code with this app can travel and enter official places, thus reducing the risk of transmission during time spent in public spaces such as on mass transport and in public spaces. If an individual tests positive for coronavirus, anyone who has recently been in the same area is notified by the Ministry of Health, which provides information for affected individuals to access health and guidance services. This app is thus also known as the "safe area code". 10,11

Field teams conducting contact tracing and digital contact tracing models have been employed in a number of countries. ${ }^{12}$ Analysis of the successes and failures of each tracing model is critical to ensure improved preparedness for future pandemics. In this context, the present study analyzed the contact tracing team model in Turkey, its obstacles and limitations, and ethical issues related to its implementation. Official and academic publications, online news, and interviews with contact tracing team members were all consulted in our analysis.

\section{Research Question}

What are the problems faced by the contact tracing teams in performing their duties? If the issues encountered by the teams were resolved and they received more support within the framework of bioethical values, would they have better results? 


\section{Method}

This is a qualitative descriptive study evaluating the contact tracing team studies directed by the Turkish Ministry of Health to identify, refer, and follow up on individuals testing positive for COVID-19 and their contacts. This research aims to obtain the opinions and suggestions of the contact tracing team members. Initially, we analyzed reports published on the websites of the Turkish Medical Association, the Turkish Academy of Science, and the Ministry of Health of the Republic of Turkey. The following reports concerning the work of contact tracing teams were then consulted in the course of our research: 1 . "Filiation: Determining the source and the agent and/or taking protection and control measures including contacts" published by the Turkish Association of Public Health Professionals (HASUDER); 2. "Covid-19 Global Outbreak Evaluation Report" by the Turkish Academy of Science (TUBA); 3. "Filiation Studies in the Process of Coronavirus Epidemic in Istanbul" by the Istanbul Medical Chamber, and; 4. "COVID-19 (SARS-CoV-2 infection) contact tracing, outbreak management, home patient monitoring and filiation" by the General Directorate of the Turkish Ministry of Health.

After evaluating the above reports, we prepared the following five questions for the contact tracing team members in order to clarify their views and elicit suggestions: 1. How could the contact tracing teams perform their duties more effectively? 2. What measures could be taken to improve the safety and security of the teams? 3 . What are your thoughts on the working conditions of the tracing teams and how could they be improved? 4 . What could the health authorities do to facilitate the work of tracing teams so that they can provide better service? 5 . What are your suggestions for easing your workload and improving your work conditions? All data collected for analysis were published between 11 March 2020 and 11 March 2021; the interviews with the contact tracing teams were also conducted within this timespan.

Interviews with members of three different contact tracing teams were conducted in person and recorded. The interviewees were asked open-ended questions about their general experiences performing their duties, the types of challenges they encountered on the job, and what kinds of ethical issues they faced that stemmed from these challenges. Feedback from members of other contact tracing teams was also gathered via interviews published in online news reports. The interviews conducted as a part of this study were analyzed together with those from abovementioned sources previously published online.

\section{Results}

The most important data concerning the field studies are the contact tracing team programs and mobile phone applications. There are three programs to control pandemics: the contact tracing field teams and two mobile app programs, the aforementioned "Life Fits in the House" (LFH) app and a second one described in detail below. The contact tracing team, however, is the primary factor in mitigating the scope of the pandemic in Turkey because it is the only program that evaluates suspected COVID-19 cases, monitors their progress, and follows up with their contacts. The LFH program has been used to identify healthy people and the rate of COVID-19 spread by area, allowing individuals to receive a health code (for example, when traveling or entering official buildings) and inform them of zones of greater risk. The second application, known as the filiation, isolation, and tracing system (FITAS) has been installed on the mobile phones of team members. ${ }^{13}$ Cases and their contacts reported to the Public Health Management System can be viewed on the FITAS application. ${ }^{11}$ Individuals in home confinement are sent a consent code via this program, such that when a patient/contact confirms this code, it indicates that they accept the conditions of their quarantine. The individual's data is then forwarded to the e-pulse system and their family physician is contacted so that the former can be monitored at home during their isolation. The quarantine dates can be checked on the LFH application and when the end date has passed the isolation process is automatically marked as "completed". ${ }^{11}$ The usefulness of these applications aside, however, the primary data analyzed in this study consisted of governmental reports and the views of contact tracing team members, who contributed most to the management of the pandemic.

In Turkey, a total of 16,000 field teams, each consisting of three personnel, were established to conduct contact tracing as part of the Ministry of Health's epidemiological investigation. The two mobile phone applications described above were created to monitor all contact tracing activities.

Reports released by various scientific and governmental agencies indicated that contact tracing teams have been successful in locating cases quickly, enabling them to isolate patients and thus reduce the spread. The teams have also succeeded in tracing the contacts of infected persons, 
administering COVID-19 tests, treating patients, following up with their contacts, and reducing infections within society. ${ }^{10,11,14}$ All reports emphasized that the COVID-19 pandemic is considered a humanitarian, medical, ecological, economic, social, and political problem. While highlighting the accomplishments of the contact tracing teams, the reports nonetheless recommended that the teams receive more support to further improve health outcomes.

The concerns expressed by members of contact tracing teams included the following: the personal protective equipment used by team members to protect themselves is sometimes inadequate and of poor quality; team members are not regularly screened for COVID-19; security risks involved with working at night; the inclusion of pregnant women and/or those with chronic illnesses in the teams; the need for teams to receive regular updates by specialist doctors, and; working conditions that do not always allow for basic needs to be met. They also stated that the Ministry of Health should keep the public informed regarding treatment and quarantine/isolation conditions. ${ }^{11}$ Despite all the preliminary preparations, the magnitude of the pandemic has led to some problems not anticipated by the teams (Box 1).

Data compiled by contact tracing teams have shown, not surprisingly, that cases tend to cluster within families. In particular, domestic transmission followed activities involving large groups of people such as birthday celebrations, weddings, funerals, and family gatherings.

The attitudes and behaviors of members of the public in reaction to contact tracing teams performing their duties have been featured in news reports and interviews. These include mistrust and/or apprehension, fear, and stigmatization, belief that the teams will provide insufficient and/or incorrect information and privacy concerns. Members of the public may not be aware of the duties of the tracing teams, how they function, and in particular, the benefits they confer on society as a whole. The public may also fail to understand individual and collective responsibilities involved in slowing/stopping the spread of COVID-19 (Box 2). ${ }^{1-10}$ Some of these reactions constitute barriers to the smooth functioning of the teams, potentially posing security issues in addition to wasting time (Box 2). ${ }^{11,12}$

\section{Discussion}

The principal goal of the contact tracing teams is to identify index cases of COVID-19 and follow up with their contacts in order to prevent transmission of the virus, informing the public and offering medical assistance
Box I Challenges Faced by Contact Tracing Teams

Q I. How could the contact tracing teams perform their duties more effectively?

Common responses: I. Based on the information received by hospitals, tracing teams make home visits to assess the situation and take necessary measures, which may include testing, treatment, and/ or isolation; they also collect information on and follow up with contacts over a 14-day period. 2. As individuals with COVID-19 are affected psychologically as well as physically, adding psychologists and/ or social workers to the teams should improve their effectiveness.

Q2. What measures could be taken to improve the safety and security of the teams?

Common responses: I. Team members must accept infection with COVID-19 as an occupational risk. 2. Spare protective clothing/gear and regular testing are necessary to ensure the health of team members. 3 . Security guards are needed to ensure the safety of team members.

Q3. What are your thoughts on the working conditions of the tracing teams and how could they be improved?

Common responses: The intense stress experienced by team members could be alleviated by extra provisions such as food, secure places to rest, safe transportation, and help for the spouses of team members with childcare and domestic duties (since contact tracing team members usually stay at hotels to avoid infecting their families).

Q4. What could the health authorities do to facilitate the work of tracing teams so that they can provide better service?

Common responses: The public should be regularly informed about the objectives and workings of the contact tracing teams, with emphasis on the gravity of the epidemic and the associated rules that should be followed.

Q5. What are your suggestions for easing your workload and improving your work conditions?

Common responses: I. Contact tracing team members should be formally notified promptly of any changes to their tasks and schedules via messaging apps. 2. Information on cases and their contacts should be carefully organized to prevent delays and lost time. 3. Weekly meetings should be held with team members, coordinating physicians, District Health Directorates, and Ministry of Health officials.

where necessary. Within this framework, the main objective of this study was to examine the societal issues faced by the teams, with the aim of maximizing the benefits provided by the latter and reduce the risks incurred on the job. Therefore, this study has focused on the challenges encountered by the teams in performing their duties during the COVID-19 outbreak in Turkey, both on an institutional level (as organs of the public health infrastructure) as well as on a societal level (as regards socioethical issues). Turkey's model of contact tracing and the lessons learned from its implementation (including its 
Box 2 Specific Examples of Issues Encountered by Contact Tracing Teams

I. Mistrust (apprehension): Upon entering a building to check on a suspected case, other residents would start to ask the teams questions such as why are you here, who are you visiting, what are you going to do, and will you perform tests, etc. The teams would sometimes be followed. When they explained that they had come to help, the residents would acknowledge that the teams were doing the right thing but continue with questions anyway.

2. Mistrust (incorrect address): Suspected cases would sometimes give incorrect addresses because their children attend school in the neighborhood where their home is located.

3. Mistrust (incorrect health information): Some members of the public would lie, claiming that they themselves or a relative/ acquaintance had COVID-19 symptoms in order to get tested, presumably out of anxiety more than any ill intent. Such unnecessary calls however are a waste of time for contact tracing teams.

4. Lack of responsibility and solidarity (individual, social, and institutional): I. Sometimes when teams would visit the home of a suspected case, the individual would not be present, having gone out, thus potentially putting others at risk. This type of carelessness and irresponsibility may pose serious problems for public health. 2. Some individuals who tested positive for COVID-19 or suspected cases would object to following the rules, stating that since others gather together socially or participate in political meetings (usually in very large crowds), it is not fair that they should have to follow the rules and stay home for two weeks, especially if they do not feel sick. Such observations highlight the fact that the rules are frequently not followed on a social or institutional level.

5. Lack of information (prefer not to wait for test results in order to avoid quarantine): Individuals who had been in contact with suspected cases would insist on taking a COVID test on condition that they be allowed to continue with their normal life if the results were negative. However, according to the algorithm of the Turkish Ministry of Health, drug treatment must be started when a COVID test is performed, without waiting for the results. Thus even if the individual tests negative, they would have already started drug treatment. Since the Ministry of Health does not allow COVID-19 drugs to be used by the same individual again within three months, if the individual later tests positive, they will not be able to undergo drug treatment at that time, potentially incurring serious complications.

6. Lack of information (demand to use COVID-19 drugs): Contacts would closely monitor each other's' situations. They would object to the proposed medications, complaining that their friends who were treated got worse, or that they were not given the same medicines and/or dosages as others. The team members would explain that each patient is evaluated and treated on an individual basis, according to their needs.

\section{Box 2 (Continued).}

7. Lack of information (demand COVID-19 test, but refuse treatment if positive):

I. Contacts under the age of 18 are neither tested nor treated by the teams, but instead referred to the hospital for treatment. However, parents frequently would insist that their children be tested but would not agree to start medication, which is contrary to the Ministry of Health's algorithm. Explaining these policies to members of the public proved to be both tiring and time-consuming for the teams.

2. Some people would call to request a test, reporting no symptoms other than a headache. The team would endeavor to determine whether any other symptoms were present. In the absence of actual symptoms, the team would explain the algorithm requiring initiation of drug treatment when testing for COVID, and those patients who become ill within the following three months could not be given the medication again. Again, communicating the necessary information to the public, while vital, could be quite tiring for the team.

8. Domestic issues: Sharing family problems: When a team visited one woman's home, they explained that in case her husband tested positive, items that they both used, such as bedding, towels, etc., would have to be separated. The woman then shared a number of personal problems that she had been experiencing with her husband.

9. Domestic issues: Crowded living conditions: Some families are very large, with ten or more people living in the same quarters. When a team visited one such family, five individuals tested positive, one of whom was in declining health and had to be taken to the hospital. In such stressful and chaotic conditions, the teams need to calm family members and help organize them to deal effectively with the situation.

10. Domestic issues: Family problems: One woman who had been identified as a contact was told that she should distinguish between all the items she and her husband used in common to prevent transmission. However, the woman explained that she could not physically distance herself from her husband due to his insistence on continuing their physical relationship even during quarantine.

II. Fear and stigmatization: Some people visited by teams were very nervous, stating that they wanted to be sure that their personal information would not be used for other purposes.

12. Threatening behavior: Sometimes neighbors of suspected cases would approach team members in a threatening manner, without wearing masks. Such individuals were warned that if such behavior continued, the team would file a complaint petition against them.

13. Attacks and harassment of contact tracing teams: Team members may be exposed to harassment or violence in addition to insults while entering and leaving their homes, as they are not provided with security personnel. More than 10 such attacks have been reported. These are a consequence of high stress levels on the part of the public combined with a lack of trust in healthcare professionals. 
success, failures, and challenges) constitute a valuable and useful tool for other countries. First introduced in 1960, Turkey's contact tracing model underwent legal revision in 2015. The model initially consisted solely of doctors and nurses, but with the rapid spread of the epidemic in 2020, dentists and other healthcare professionals began taking part in contact tracing fieldwork. During the Ebola epidemic, contact tracing represented a critical undertaking on a global scale; the WHO even published a contact tracing report on the identification, assessment, management, and prevention of Ebola. ${ }^{15}$

With the COVID-19 outbreak, the contact tracing model has evolved and attracted more attention. The current model, which involves fieldwork carried out by healthcare professionals, has been implemented with some modifications in various countries. South Korea built a quick response team of 298 public health workers to identify contacts and isolate them. ${ }^{16}$ The Netherlands and Austria created "Outbreak Management Teams" (OMT) which included specialists and experts from different backgrounds to begin contact tracing and isolating individuals. ${ }^{17}$ In India, contact tracing teams have employed university students or graduates, while the University of Pennsylvania in the US recruits student volunteers for its teams. The Turkish model is based on legal regulations passed in 1960 and 2015 and is managed throughout the country by the Ministry of Health. Originally consisting only of doctors and other healthcare professionals (such as nurses), due to the high numbers of patients and suspected cases resulting from the current pandemic, dentists, 5th and 6th-year medical students, residents, and doctoral students in health care have also been recruited to the teams.

In the meantime, other countries have also developed digitally-based contact tracing models. As the transmission of COVID-19 is airborne, this has created serious problems for healthcare professionals and the public, necessitating additional efforts beyond pre-existing practices. Mobile phone GPS trackers, electronic health records, credit card transactions, and CCTV (closed-circuit television) footage have all been used to identify index cases and their contacts. ${ }^{12,18,19}$ Digital methods together with contact tracing field teams employed in countries such as South Korea, the Netherlands, the United States, Australia, and India have proven to be effective means of tracking the spread of the virus. However, Turkey's digital application model has not achieved the results of those used in developed countries, as it lacks sufficient infrastructure (including the necessary devices and training) to support such innovative high-tech methods. For this reason, Turkey continues to rely on mobilizing contact tracing teams to conduct the required fieldwork. Despite developments in digital applications that could be utilized to aid in tracking the virus, the contact tracing field model remains a more effective and functional model for many countries. Nonetheless, as elaborated above, contact tracing fieldwork involves numerous challenges for both healthcare professionals involved in this work and suspected cases/ contacts.

The present study is of limited scope because of minimal access to contact tracing teams as well as a lack of reliable data on the pandemic in many countries, including Turkey. However, the data obtained are nevertheless consistent with reports published in various media in many countries involving the challenges and issues pertaining to contact tracing. The pandemic has affected all segments of society both in socioeconomic and psychological terms, triggering serious concerns about both physical and mental health, as well as about people's livelihoods. Thorough evaluation of the data on the work performed by contact tracing teams (while being cognizant of any deficiencies in the data) in terms of patient outcomes and the healthcare system in general will allow for better preparation for future pandemics. Therefore, the work of contact tracing teams represents a critical step in combating the spread of the virus.

Although health authorities in Turkey frequently released information on the virus and its treatment, along with announcing measures to prevent its spread, they failed to incorporate certain basic bioethical values, namely informed consent. Obtaining public consensus on issues of public health is a precondition for implementing basic measures during a pandemic. Indeed, individuals arguing from different moral and religious traditions may agree to accept the implementation of extraordinary measures during a pandemic for the sake of protecting public health. In addition to social consensus, compromise on the part of the public may also be necessary during a pandemic, requiring certain sacrifices. At the center of this concept is the idea of mutual compromise for mutual benefit. Here, both the sacrifices of healthcare professionals and the forgoing of certain routine activities and customs by the general public (eg, funeral services, meetings, wedding parties, etc.) provide benefits to all.

Due to a lack of knowledge on the part of the public concerning the ethical and social values related to the 
pandemic, the full implications of the latter are not well understood; this deficiency is manifested in all layers of society. As can be seen in the data collected for this study, both healthcare professionals and the general public have encountered numerous unexpected challenges and difficulties in the face of the pandemic. Finding ways to resolve the issues broached by healthcare professionals urgently and within the framework of bioethical values will play a key role in improving public healthcare services during the pandemic.

The challenges faced by contact tracing teams in Turkey, summarized in Box 1 above, have negatively affected the enthusiasm of team members for their work, as well as their confidence in society in general as a result of inadequate compensation for the sacrifices they make in the name of public health. Reviewing the issues presented in Box 1, the main problem is revealed to be the lack of basic bioethical values regarding social consensus. Despite all the available technology and medical knowledge, differences in peoples' abilities to fully grasp the implications of the pandemic negatively affect the battle against it.

The societal challenges reported by the contact tracing teams involved both emotional and intellectual aspects (Boxes 1 and 2). These issues derived from a disregard of basic bioethical values on the part of both the general public and health authorities. These bioethical values include the following:

\section{Truthfulness and Information}

The dissemination of information is central to the functioning of the modern information society and is considered by health authorities to be critical in the management of pandemics. However, the findings presented in both boxes emphasize the question of trust inherent in the public's understanding of what is truthful. Health authorities must be perceived as being truthful, and the information they impart accurate and consistent, in order to gain public trust. $^{20}$

\section{Reciprocity}

One of the central tenets of public health ethics, this principle should be explained in such a way that the public understands that the relevant measures to be taken are for their benefit, and should not be viewed as a burden or a limit on individual activities.

\section{Benefit}

Turkey's contact tracing model has been effective in disrupting the chain of transmission by tracking suspected cases and identifying their contacts. In addition, the teams dispense information on COVID-19 to suspected cases and their family members as well as to contacts, providing instant answers to their questions and even social support. For this reason, the contact tracing model functions not only as a source of medical information for the affected public but also provides social/psychological as well as medical support.

\section{Responsibility}

Both boxes reveal serious deficiencies regarding the ability of tracing teams to fulfill their responsibilities. With respect to public health issues, the concept and practice of responsibility require each individual and society as a whole to understand and fulfill their duties as a voluntary obligation, and even to be held accountable when necessary. ${ }^{21,22}$ Requests and/or recommendations by health authorities to abandon or restrict existing habits, traditions, and practices must be perceived by the public as both necessary and even desirable (the better to combat the spread of the virus). Awareness of responsibilities at the individual, national, and global level is critical in the fight against the pandemic.

\section{Solidarity}

Achieving public solidarity in the face of a pandemic requires a firm grasp of the concept of reciprocity, the active participation of individuals and societal institutions and respectful communication between them, and psychosocial support. Understanding the concepts of solidarity, responsibility, and reciprocal benefits by all layers of society as well as authorities will serve to protect the dignity of the individual and healthcare worker, leading to a decrease in threats, attacks, and harassment and the development of supportive behaviors such as compassion in lieu of stigmatization.

\section{Stigmatization}

Outbreaks of disease may result in a crisis situation, revealing the prejudice and hostility of some social groups against others. Consequently, some individuals may prefer to hide their disease, sharing their condition only with authorized healthcare professionals. The importance and benefits of the basic bioethical concepts outlined above are 
all well understood by healthcare professionals; extending this understanding to the general public for inclusion in their system of values will aid in the resolution of public health problems such as pandemics. ${ }^{23}$

In conclusion, the availability of technical and medical equipment to protect public health remains limited in Turkey, as the COVID-19 pandemic has made abundantly clear. Therefore, the principles of public health ethics constitute a means by which individuals and the public as a whole may be protected from harm, by promoting the highest attainable standard of health and contributing to a strong commitment to social action. Securing the active participation of the public in this process leads to a better grasp of the risks and challenges posed by the pandemic, while also helping the public to understand that measures taken to protect public health are also aimed at protecting the health of each individual, enabling healthcare professionals to perform their duties more effectively.

\section{Limitations}

This is a qualitative descriptive study. The data presented herein are limited to reports published by various Turkish associations as well as the Turkish Ministry of Health and online news services between 11 March 2020 and 18 April 2021, along with interviews conducted with members of contact tracing teams. Therefore, our findings reflect only the data gathered from the aforementioned sources and the viewpoints of the members of the contact tracing teams whom we interviewed.

\section{Data Sharing Statement}

All data relevant to the study are included in the article.

\section{Ethical Approval}

This study was designed and conducted in compliance with the principles of the Declaration of Helsinki. The study protocol and all study-related materials were approved by Van Yüzüncü Yıl University Clinical Research Ethics Committee 25.12.2020, Decision No. 17. All participants signed an informed consent form that included a confidentiality agreement.

\section{Author Contributions}

All authors made a significant contribution to the work reported, whether that is in the conception, study design, execution, acquisition of data, analysis and interpretation, or in all these areas; took part in drafting, revising or critically reviewing the article; gave final approval of the version to be published; have agreed on the journal to which the article has been submitted; and agree to be accountable for all aspects of the work.

\section{Disclosure}

Dr Barış Sarp Sevimli report non-financial support from Hacettepe university, during the conduct of the study. The authors report no other conflicts of interest.

\section{References}

1. World Health Organization. The top 10 causes of death [Internet]; 2020 [cited February 6, 2021]. Available from: https://www.who.int/ news-room/fact-sheets/detail/the-top-10-causes-of-death. Accessed October 14, 2021.

2. World Health Organization. Contact tracing in the context of COVID-19. WHO Guidel [Internet]; 2020;2019(May, 10): 1-7. Available from: https://www.who.int/publications-detail/contacttracing-in-the-context-of-covid-19. Accessed October 14, 2021.

3. Proust A. Études d'hygiène - Épidémies anciennes et épidémies modernes - les nouvelles routes des grandes épidémies. Rev des Deux Mondes 1893 [Internet]; 1893:120. Available from: https://fr. wikisource.org/wiki/Études_d'hygiène_-_Épidémies_anciennes_et_ épidémies_modernes,_les_nouvelles_routes_des_épidémies. Accessed October 14, $20 \overline{2} 1$.

4. Marchand M. De la doctrine des principes contagieux et des maladies contagieuses, considérée dans ses rapports avec le système de la prophylaxie publique. Gaz Méd d'Orient Paris. 1836;32(6):283.

5. Halk Sağlığı Uzmanları Derneği (HASUDER). Filiation: Determining the Source and the Agent and/or Taking Protection and Control Measures Including Contacts. Ankara-Turkey: Kavramlar ve Tanımlar Rehberi, Halk Sağlığı Uzmanları Derneği (HASUDER); 2020.

6. Sağlık Bakanlığı TC. Toplum Sağlığı Merkezi ve Bağlı Birimler Yönetmeliği. Resmî Gazete; 2015.

7. Sağlık Bakanlığı TC. Bulaşıcı Hastalıklar İle Mücadele Rehberi itle [Internet]; 2017. Available from: https://hsgm.saglik.gov.tr/dosya/ mevzuat/genelge/\%0ABulasici-Hastaliklar-ile-Mucadele-RehberiGenelgesi-2017-11.pdf. Accessed October 14, 2021.

8. Sağlık Bakanlığı TC. Sağlık Bakanlı̆̆ı [Internet]. Sağlık Bakanlığı; 2020:1. Available from: https://www.saglik.gov.tr/yazdir? B6CE947A484C4BFEB73D11934A42B04B. Accessed October 14, 2021.

9. Sağlık Bakanlığı TC. COVID-19 algoritmalar [Internet]. TC Sağlık Bakanlığ1; 2021 [cited March 10, 2021]. Available from: https:// covid19.saglik.gov.tr/TR-66303/covid-19-algoritmalar.html. Accessed October 14, 2021.

10. Turkish Academy of Science (TUBA). Covid-19 Küresel Salgin Değerlendirme Raporu [Internet]. Ankara-Turkey; 2020. Available from: http://www.tuba.gov.tr/tr/haberler/akademiden-haberler/tubacovid-19-kuresel-salgin-degerlendirme-raporu-kitaplastirildi. Accessed October 14, 2021.

11. İstanbul Tabip Odası. İstanbul'da Koronavirüs Salgını Sürecinde Filyasyon Çalışmaları [Internet]. istanbul; 2021. Available from: https://www.istabip.org.tr/site_icerik/2021/ocak/filyasyon_rapor.pdf. Accessed October 14, 2021.

12. Lo B, Sim I. Ethical framework for assessing manual and digital contact tracing for COVID-19. Ann Intern Med. 2021;174 (3):395-400. doi:10.7326/M20-5834

13. World Health Organization. Regional Office for Europe. Turkey's response to COVID-19: first impressions [Internet]; 2020. Available from: https://apps.who.int/iris/bitstream/handle/10665/335803/WHOEURO-2020-1168-40914-55408-eng.pdf. Accessed October 14, 2021. 
14. T.C. Sağlık Bakanlığı Halk Sağlığı Genel Müdürlüğü. COVID-19 (SARS-CoV-2 enfeksiyonu) temaslı takibi, salgın yönetimi, evde hasta izlemi ve filyasyon [Internet]. Ankara-Turkey; 2021. Available from: https://covid19.saglik.gov.tr/Eklenti/40231/0/covid-19rehberite maslitakibievdehastaizlemivefilyasyonpdf.pdf. Accessed October 14, 2021.

15. World Health Organization. Implementation and management of contact tracing for ebola virus disease; September, 2015:1-36. Available from: http://apps.who.int/iris/bitstream/10665/185258/1/WHO EVD_Guidance_Contact_15.1_eng.pdf?ua=1. Accessed October 14, 2021.

16. Bae S, Kim H, Jung TY, et al. Epidemiological characteristics of COVID-19 outbreak at fitness centers in Cheonan, Korea. $J$ Korean Med Sci. 2020;35(31):1-9. doi:10.3346/jkms.2020.35.e288

17. Stuart RL, Zhu W, Morand EF, Stripp A. Breaking the chain of transmission within a tertiary health service: an approach to contact tracing during the COVID-19 pandemic. Infect Dis Health. 2021;26 (2):118-122. doi:10.1016/j.idh.2020.11.003

18. Centers for Disease Control and Prevention (CDC). Contact Tracer COVID-19 Response Job Description Template; 2020:1-3.
19. Beidas RS, Buttenheim AM, Feuerstein-simon R, et al. Optimizing and implementing contact tracing through behavioral economics. $N$ Engl J Med. 2020:1-10. Available from:/pmc/articles/ PMC7371277/?report=abstract\%0Ahttps://www.ncbi.nlm.nih.gov/ pmc/articles/PMC7371277/. Accessed October 14, 2021.

20. Chan HY. Reciprocal trust as an ethical response to the COVID-19 pandemic. Asian Bioeth Rev. 2021:0123456789. doi:10.1007/s41649021-00174-2

21. Davies B, Savulescu J. Solidarity and responsibility in health care. Public Health Ethics. 2019;12(2):133-144. doi:10.1093/phe/phz008

22. Sevimli S. The evaluation of public health ethics, individual, collective and state with institutional, responsibilities and obligation during COVID-19 pandemics through online media reports in Turkey. Eubios J Asian Int Bioeth EJAIB. 2021;31(2):124-136.

23. Courtwright A. Stigmatization and public health ethics. Bioethics. 2013;27(2):74-80. doi:10.1111/j.1467-8519.2011.01904.x
Journal of Multidisciplinary Healthcare

\section{Publish your work in this journal}

The Journal of Multidisciplinary Healthcare is an international, peerreviewed open-access journal that aims to represent and publish research in healthcare areas delivered by practitioners of different disciplines. This includes studies and reviews conducted by multidisciplinary teams as well as research which evaluates the results or conduct of such teams or healthcare processes in general. The journal

\section{Dovepress}

covers a very wide range of areas and welcomes submissions from practitioners at all levels, from all over the world. The manuscript management system is completely online and includes a very quick and fair peer-review system. Visit http://www.dovepress.com/testimonials. php to read real quotes from published authors. 